\title{
A dental practice manager's life
}

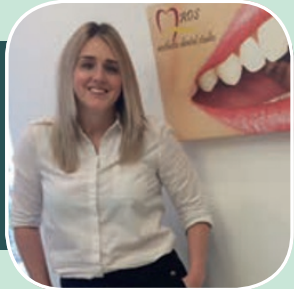

\begin{abstract}
Anne-Marie Saxton, 35, is a practice manager and treatment coordinator in Nottingham, and also her practice's oral health educator and referral coordinator. Anne-Marie has a 5-year-old daughter called Freya.
\end{abstract}

I get up at 6:30 am and usually have a strong coffee to wake me up, followed by a selection of fruit and yoghurt. Work is half an hour away and I usually take the bus as it tends to get me into the city centre quicker than driving. This way I also get to check my emails on the way in.

I am lucky enough to work part time at present because of my child care commitments. I work generally $9: 30$ am to 2:30 pm Monday to Thursday in practice. This can differ depending on the needs of the practice.

My days can differ dramatically week to week. Rather than planning my duties weekly I tend to plan my month ahead for specific tasks.

In a typical month, to begin with I do a full practice check - checking the practice room to room - ensuring the team has completed their tasks. This includes spotchecks, cleaning audits, reception audits and decontamination room audits. As I do this I check all compliance tasks are up to date. I have an app with all tasks on it so I know what I need to do for the following month and can work this into my calendar. These are tasks such as record card and radiograph audits, policy reviews and significant event reviews.
I also do finance checks, look at practice performance and review the last month. I also review interest free credit accounts and patient payment plan activity.

I am also responsible for software and appointment book management; staff one to ones/rota updates/personal file review/ training review and payroll. I prepare for and deliver staff meetings and in house training; review and prepare marketing activity, promotions and advertising; do stock takes and order stock.

With all of the above tasks, I'll plan my month out then it gives me time to fit in general day to day tasks and appointments.
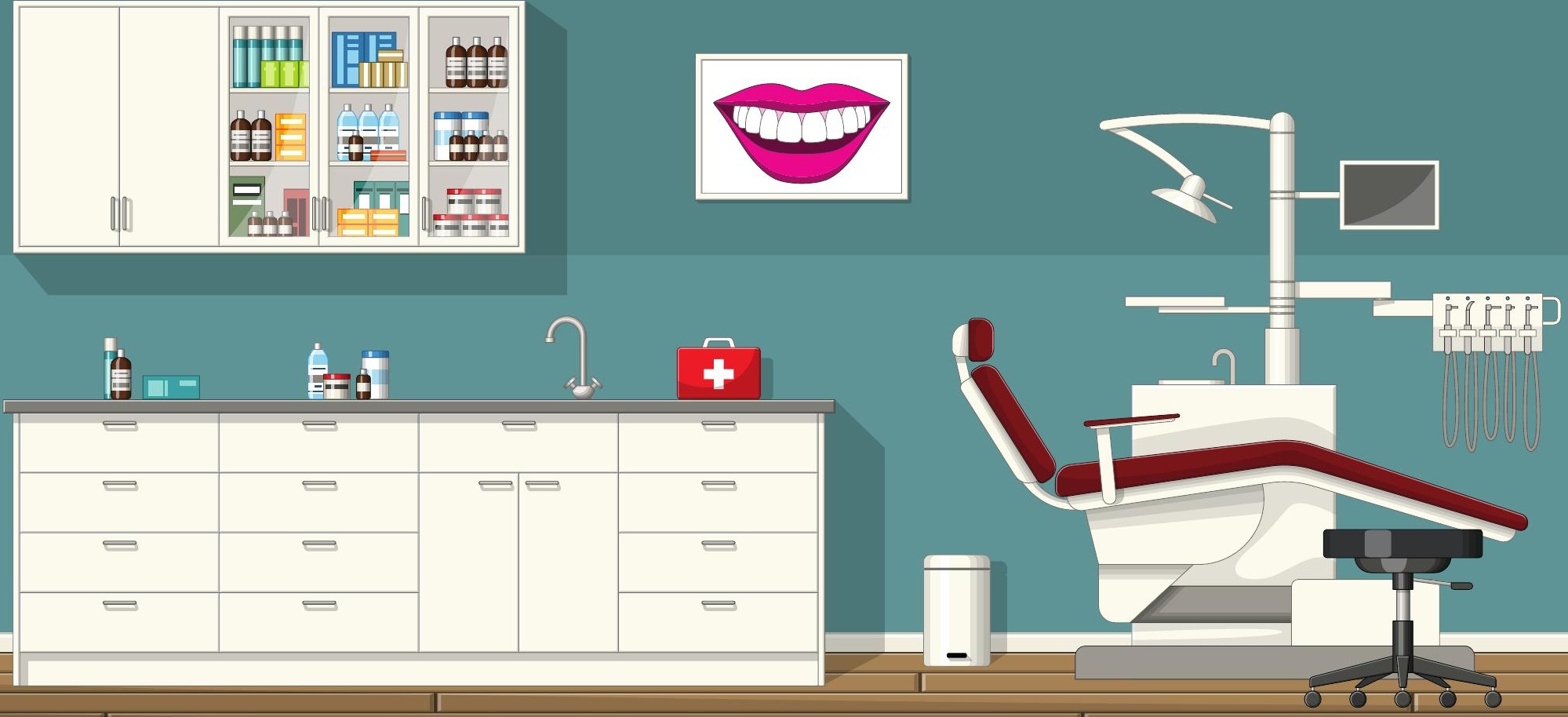
Currently at practice I have the following appointments to offer our patients:

- Treatment coordinator appointments - to discuss treatment plans and finance options

- Oral health appointments - to offer advice to patients to improve their oral health

- Nervous patient appointments - to show patients the practice and explain what will happen at each appointment and see if the practice can do anything to help the patient

- OPG and general referral correspondence and also taking any OPG referrals sent to us by other practices.

I became a trainee dental nurse in 2004. I fell into it completely by chance at a time when I was deciding what to do. Since qualifying I have completed post-graduation certificates in dental radiography, oral health education, fluoride application and impression taking. In my current job I love the patient contact, so I particularly enjoy oral health instruction sessions and the nervous patient sessions, but I also like the compliance side of my role. I enjoy organising and helping develop team members. I like being able to help staff learn new skills and explore the different aspects of their job role.

A more challenging aspect to my job is making time to spend one on one quality time with staff within the working day, to really help develop them. We have seven people in our practice: the lead dentist and owner; a clinician who performs our implant cases; a dental hygienist; two qualified dental nurses; one trainee dental nurse; and one practice cleaner. Recently a doctor also joined our team to offer facial aesthetics and a pain management clinic. This service is fairly new to the practice but also exciting as we have not offered this service before.

We see a wide range of patients including children, students, professionals, families and the elderly. We are currently taking new NHS patients, we are a Denplan practice and we receive referrals from dental practices in the area as well.

In our area we are lucky to have the 'The Smile Squad' offered by the oral health promotions team which I am a member of. It offers events and training days helping us to promote oral health not only in our practice but also in the community. Previously this has involved attending schools or nurseries to help teach good oral health messages; I hope to do this again in 2017.

At the practice we also have various special events to promote different services, such as Invisalign or tooth whitening. We also try and have on-going sessions for our patients - we offer all patients oral health checks where after they have seen the dentist if they need further advice on how to improve their oral health they can book in to a session where toothbrush technique/interdental cleaning/diet and social habits are discussed. The focus at practice is very much based on preventative treatment.

We also offer nervous patients tours before they visit the dentist or attend a treatment appointment. At this appointment we will talk through what exactly will happen, show any instruments or equipment which may be used, and try and find out what exactly makes the patient nervous - to see if we can take any additional steps to make their journey with us more enjoyable.

Due to my short work days, I don't take a lunch break. I make sure I have something ready for when I get home. I leave work at 2:30 pm daily to collect my daughter from school then get home for around 4 or depending on after school activities, around $6 \mathrm{pm}$.

As well as my job, I am also assistant chair of the school PTA in which I spend time organising events and raising money for the school.

I am currently doing an online photography course and try to practise my photography as much as I can. I have recently taken photographs for our practice website and am soon to take staff portraits for social media.

This year I would like to start a dental nurse extended duties course or study club, offering training to local dental nurses in dental photography or perhaps along the lines of how to fit oral health education into a busy dental practice. Outside work I would like to finish my photography course and perhaps turn my hobby into a business.

Since having my daughter, I am very aware of the importance of reading food labels. I try to teach Freya about reducing sugar and eating healthy snacks.

Although I finish work fairly early I try to study my online photography course or do CPD in the evenings. Most of the CPD my practice has is sourced free online or available through the Midlands Deanery. We also have a lot of inhouse training in the form of lunch and learns.

I usually go to bed between $11 \mathrm{pm}$ and midnight.

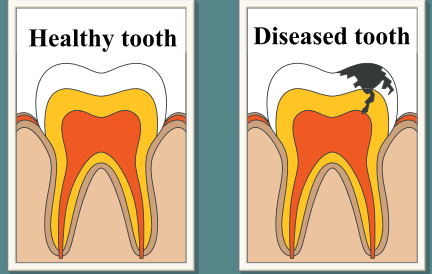

\section{'I LOVE THE PATIENT CONTACT,}

SO I PARTICULARLY ENJOY ORAL HEALTH

INSTRUCTION SESSIONS AND THE NERVOUS

PATIENT SESSIONS, BUT I ALSO LIKE THE

COMPLIANCE SIDE OF MY ROLE.' 